\title{
Palmar plating of distal radius fractures : 3-year follow-up with titanium and PEEK plates give similar outcomes
}

\author{
Josephine Berger-Groch, Ann-Christin Stodtmeister, Jan P. Petersen, Michael Hoffmann
}

From the Department of Trauma and Orthopaedic Surgery, University Medical Center Hamburg-Eppendorf, Hamburg, Germany

\begin{abstract}
A variety of different plate designs and materials are available to treat distal radius fractures. This study evaluates clinical results with a carbon fibrereinforced (CFR)-polyether ether ketone (PEEK) plate in comparison to a standard titanium plate.

Thirty-one distal radius fractures were included in this randomised controlled trial. Five fractures were classified as type A, 6 as type $B$ and 20 as type $C$, in accordance with the $\mathrm{AO}$ classification. Patients were randomly allocated into two groups : 15 patients for titanium palmar plating (TPP) and 16 patients for PEEK palmar plating (PPP). Follow-up examinations were set at 2 weeks, 6 weeks, 3 months, 6 months and 3 years postop.

In terms of wrist range of motion, radiological evaluation (alignment and fracture healing), DASH score (Disabilities of Arm, Shoulder and Hand), and VAS (visual analogue scale), no statistically significant differences were detected between the two groups, at all follow-up intervals.

PEEK palmar plating and titanium plates give equivalent clinical and radiological outcomes up to 3 years follow-up.
\end{abstract}

Keywords : distal radius fracture; carbon; PEEK ; radiolucency ; titanium plate.

Ethics approval and consent to participate: The study was authorised by the local ethics committee (PV4664) and was performed in accordance with the ethical standard of the 1964 Declaration of Helsinki as revised in 2000.

Consent for publication: The patients gave informed consent prior to being included in the study.

Conflict of interest: The authors declare no conflict of interest with regard to the content of this study.

\section{INTRODUCTION}

For patients with an unstable and comminuted distal radius fracture, open reduction and internal fixation by plating is an accepted treatment option, as this can assure immediate stable fixation and allows early mobilisation. A variety of implants are available that use different materials. Implants made of polyether ether ketone (PEEK) exhibit some decisive advantages compared to conventional titanium implants : (1) suitability for patients with metal allergies, (2) fewer problems with radiopacity and (3) fewer artefacts on magnetic resonance imaging (1). It has also been shown that this material provides more appropriate strength, toughness and better fatigue resistance than do metallic implants (2). Moreover PEEK plates are highly resistant to

Josephine Berger-Groch ${ }^{1}$, MD

Ann-Christin Stodtmeister ${ }^{1}$, MD

Jan P. Petersen ${ }^{1}$, MD

- Michael Hoffmann ${ }^{1,2}$, MD

${ }^{1}$ Department of Trauma and Orthopaedic Surgery,

University Medical Center Hamburg-Eppendorf, 20246

Hamburg, Germany.

${ }^{2}$ Department of Orthopaedic and Trauma Surgery, Asklepios St. Georg, Hamburg, German.

Correspondence : : Dr. Josephine Berger-Groch, Department of Trauma and Orthopaedic Surgery, University Medical Center Hamburg-Eppendorf, Martinistraße 52, 20246 Hamburg, Germany. Phone : +49-40 7410 18418. Fax : +4940741054569 .

Email : j.berger@uke.de

- 2021, Acta Orthopædica Belgica.

Acta Orthopædica Belgica, Vol. 87 - 3 - 2021 
corrosion and have a favourable strength-to-weight ratio (3). The bending structural stiffness of the distal volar plate implant made of carbon fibrereinforced (CFR) PEEK is 0.542 - versus 0.376 $\mathrm{Nm}^{2}$ for titanium Depuy's DVR anatomical volar plate - and exhibits no material failure after one million fatigue cycles (4).

Most standard plates for palmar plating of the distal radius are made of titanium. In order to evaluate differences between the standard plate and plates made of CFR-PEEK, we have conducted a clinical study with a 3 year follow-up period.

\section{MATERIALS AND METHODS}

A prospective randomised controlled trial was conducted, enrolling patients treated for unstable distal radius fractures with palmar plating in 2014 (Jan.-Nov.). After written consent by the patient, randomisation was performed during the treatment in the emergency department - by picking out one of a stack of prepared envelopes. Patients were randomly allocated into 2 groups : Titanium palmar plating (TPP) and PEEK palmar plating (PPP). Table I gives exact information on patient selection.

Table I. - Flowchart with information on patient selection

\begin{tabular}{|c|}
\hline \multicolumn{1}{|c|}{84 patients met inclusion criteria } \\
\hline$-\quad 44$ patients declined \\
\hline 40 patients \\
\hline$-\quad 9$ did not take part in follow-up \\
\hline $\mathrm{n}=31$
\end{tabular}

The inclusion criteria were defined as: (1) unilateral unstable distal radius fractures Types A 2 to C3 (see Fig. 1) (2) with persistent displacement after a reduction attempt and (3) age $\geq 18$ years. Exclusion criteria were bilateral fractures, psychiatric disorder, and a medical condition prohibiting operation (like acute infection, skin defects, cardiac arrest).

The following mechanisms were documented: 21 simple falls on outstretched hands, 4 bicycle accidents, 5 sport injuries and 1 fall from $2 \mathrm{~m}$ height.

The polyether ether ketone plates (PEEK Power, Distal Radius Plate, Arthrex ${ }^{\circledR}$, Florida, USA) were

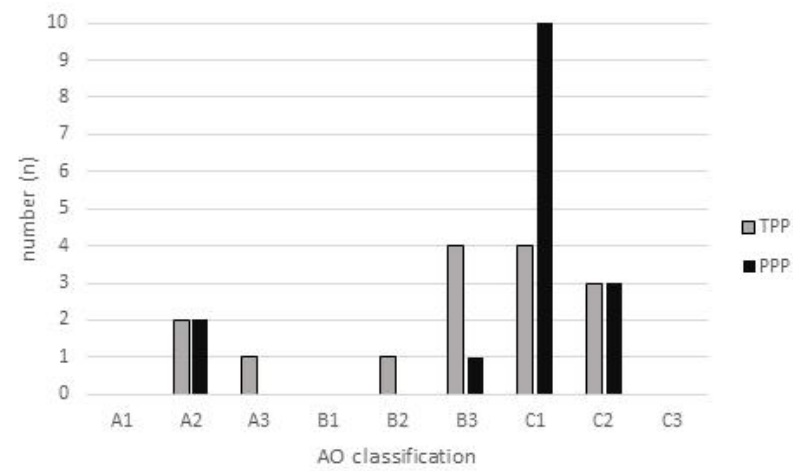

Figure 1. - Distribution of fracture pattern according to AO classification shown for TPP (=titanium palmar plating) and PPP (=Polyether ether ketone (PEEK) palmar plating).

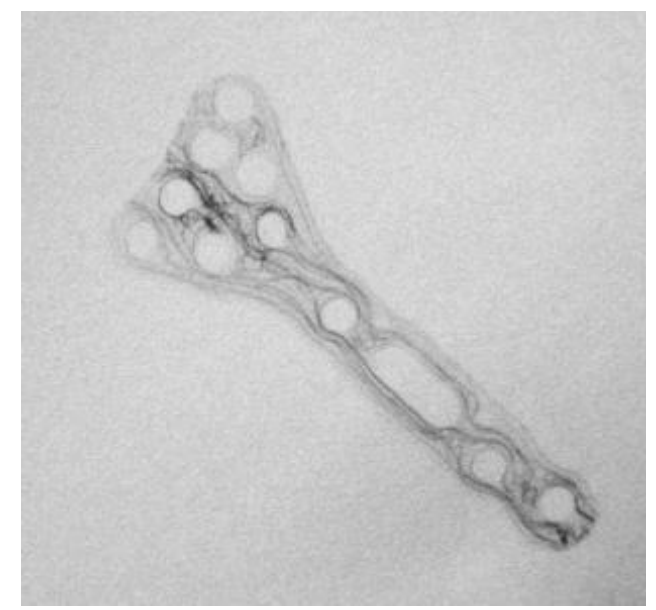

Figure 2. - Fluoroscopy of PEEK Power, Distal Radius Plate (Arthrex ${ }^{\circledR}$, Florida, USA) on a table in a.p. to visualise its presentation.

manufactured by injection moulding of CFR-PEEK and incorporated 7 holes in the distal rows for 2.7 locking screws on the distal part of the plate, and 4 different holes for 2.7 locked screws on the diaphysis (see Fig. 2). The "VariAx distal radius plate" (Stryker $\AA$, Michigan, USA) was used as the titanium option. This anatomical volar plate is available with a range of locking and non-locking screws as well as pegs from 2-2.7 mm. Although implant costs vary between hospitals and purchasing syndicates, for the purpose of this study, the two implants were priced equally. The two plates had similar designs, as shown in Figs. 3 and 4.

All operations were performed by two senior surgeons (author: JPP and MH) using the standard 


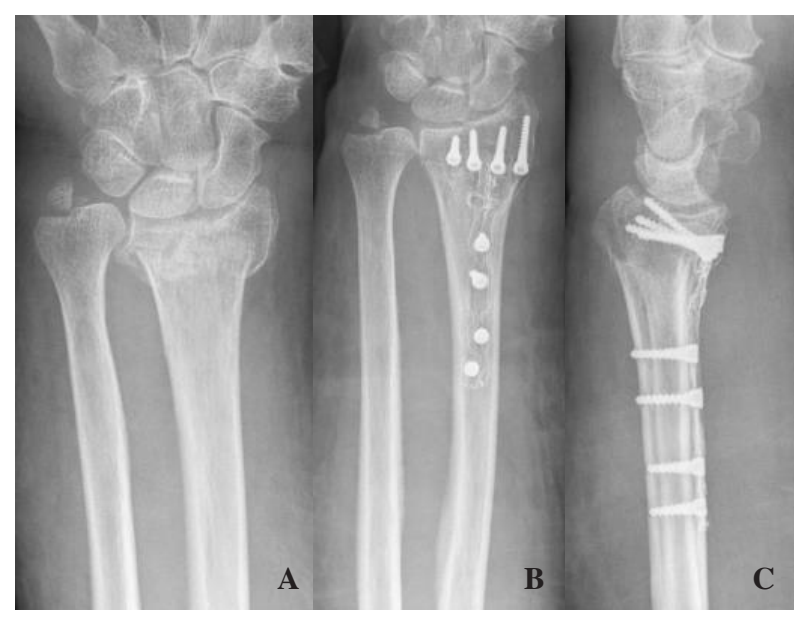

Figure 3. - 71-year old male patient after distal radius fracture after a fall. Surgery with PEEK Power, Distal Radius Plate (Arthrex ${ }^{\circledR}$, Florida, USA). A. preoperative X-ray wrist a.p. B. postoperative X-ray wrist a.p. C. postoperative X-ray wrist lateral.

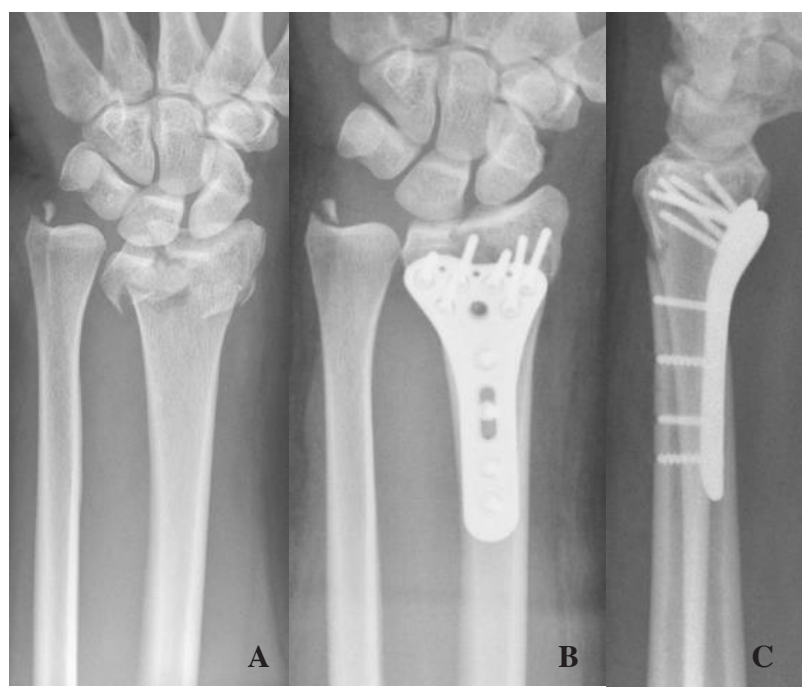

Figure 4. - 49-year old female patient after distal radius fracture from falling from a bicycle Surgery with VariAx distal radius (Stryker $\AA$, Michigan, USA). A. preoperative X-ray wrist a.p. B. postoperative X-ray wrist a.p. C. postoperative $\mathrm{X}$-ray wrist lateral.

Henry's palmar approach. The plate was placed directly onto the radius after reduction of the fracture, and the positions of plate and screws were confirmed by intraoperative fluoroscopy. Finally, the pronator quadratus muscle was sutured, allowing almost complete coverage of the plate.
Operation time from skin incision till last suture was documented for both groups.

Radiation exposure of the C-arm device used during surgery was recorded at the end of each procedure.

A postoperative below-elbow wrist splint was applied for 2 weeks in all cases. Sutures were removed 2 weeks after the operation and physiotherapy was started. A wrist brace was then applied for four weeks.

X-rays with anteroposterior (a.p.) and lateral views of the distal radius were performed in our outpatient clinic after 2 days, 2 weeks and 6 weeks, in order to evaluate plate position, reduction maintenance and fracture healing. A clinical evaluation of passive and active range of motion (ROM) and functional outcome was performed by a blinded physician (author: ACS) in our outpatient clinic 2 weeks, 6 weeks, 12 weeks and 6 months postoperatively. ROM was determined using a goniometer. Functional outcome was measured via the Disabilities of Arm, Shoulder and Hand (DASH) questionnaire in the German version $(5,6)$. Patients answered the score after 2 weeks, 6 weeks, 3 months, 6 months and 3 years postoperatively. At the same times, patients were asked to rate their pain on the visual analogue scale (VAS) between 0-10. (author: ACS)

Two independent investigators (author : JBG and ACS) analysed patient files with respect to gender, age, type of operation, complications, outcome and radiographs. Radial inclination, palmar tilt and ulnar variance was measured. Any discrepancy was discussed, and a final measurement was agreed upon.

\section{Statistical analysis}

All statistical analyses were performed with SPSS statistical software version 22.0 (SPSS, Chicago, IL). P values $<0.05$ (2-sided) were considered statistically significant. Whenever the expected numbers in cell entries were smaller than 5, Fisher's exact test was applied to calculate $p$ values. The Mann-Whitney U test was performed to test for differences. In order to address the comparability of the two groups, descriptive statistics were presented 
as proportions for categorical variables and means plus standard deviations for continuous variables.

\section{RESULTS}

31 patients (10 male, 21 female) met the inclusion criteria, with an average age of 59 years at the time of injury (mean : 59.23 years \pm SD 14.25 ; range 2486). The TTP subgroup consisted of 4 male and 11 female patients and the PEEK subgroup of 6 male and 10 female patients. 12 fractures were on the right side and 19 fractures on the left side. The mean time until operation was 5 days $(\mathrm{SD} \pm 2.12$, range $0-11)$. The operation took a mean of $63.77 \mathrm{~min}$ ( $\mathrm{SD} \pm 13.43$, range $27-141 \mathrm{~min}$ ), without significant differences between the two groups $(\mathrm{p}=0.52)$. The intraoperative radiation exposure was $24.42 \mathrm{~s}$ (SD : \pm 26.91 , range : 0-146 sec). No significant difference in radiation exposure was detected between the TPP and PPP groups $(\mathrm{p}=0.28)$. Moreover, there was no significant difference between the two groups with respect to range of movement at 6 months follow-up $(\mathrm{p}>0.05)$.
During the follow-ups, 3 complications were recorded: One case of complex regional pain syndrome in the TPP group, and one case in each group of temporary paraesthesia in the hand. In the final follow-up, the implant was removed without medical indication at the request of $6 / 31$ patients 2 in the TPP group and 4 in the PPP group. During the removal of the implant, no differences between the groups were found with respect to soft tissue status, as evident in adhesions, scarring or material residues. The mean time till implant removal was 26.5 months ( $\mathrm{SD} \pm 17.66$, range $12-52$ months). No plate or screw dislocations or failures were recorded.

No radiographic difference regarding plate position and reduction maintenance were detected during follow-up. Radiographic union was documented for all treated fractures with no significant differences between the two groups ( $p>0.05$ ). No pseudarthrosis and no loss of the achieved fracture reduction was detected. After 6 weeks, all fractures were healed.

Table II summarises the comparison between the two groups. In the PPP group, one patient was unable to participate in the 3 years follow-up due

Table II. - Data overview comparing groups with TPP (=titanium palmar plating) and PPP (=polyether ether ketone (PEEK) palmar plating

\begin{tabular}{|c|c|c|}
\hline & TTP group $(n=15)$ & PPP group $(n=16)$ \\
\hline \multicolumn{3}{|c|}{ average range of motion after 6 months } \\
\hline - extension & $65^{\circ}\left(\mathrm{SD} \pm 8.48 ;\right.$ range: $\left.55^{\circ}-80^{\circ}\right)$ & $64^{\circ}\left(\mathrm{SD} \pm 14.60 ;\right.$ range: $\left.30^{\circ}-80^{\circ}\right)$ \\
\hline - flexion & $63^{\circ}\left(\mathrm{SD} \pm 11.68 ;\right.$ range: $\left.40^{\circ}-80^{\circ}\right)$ & $68^{\circ}\left(\mathrm{SD} \pm 11.72 ;\right.$ range $\left.45^{\circ}-90^{\circ}\right)$ \\
\hline - radial deviation & $25^{\circ}\left(\mathrm{SD} \pm 7.20 ;\right.$ range: $\left.10^{\circ}-35^{\circ}\right)$ & $28^{\circ}\left(\mathrm{SD} \pm 6.06 ;\right.$ range $\left.20^{\circ}-40^{\circ}\right)$ \\
\hline - ulnar deviation & $44^{\circ}\left(\mathrm{SD} \pm 7.74 ;\right.$ range: $\left.30^{\circ}-60^{\circ}\right)$ & $41^{\circ}\left(\mathrm{SD} \pm 6.42 ;\right.$ range $\left.30^{\circ}-55^{\circ}\right)$ \\
\hline - supination & $79^{\circ}\left(\mathrm{SD} \pm 14.23 ;\right.$ range: $\left.40^{\circ}-90^{\circ}\right)$ & $81^{\circ}\left(\mathrm{SD} \pm 16.33 ;\right.$ range $\left.30^{\circ}-90^{\circ}\right)$ \\
\hline - pronation & $89^{\circ}\left(\mathrm{SD} \pm 2.80 ;\right.$ range: $\left.85^{\circ}-90^{\circ}\right)$ & $89^{\circ}\left(\mathrm{SD} \pm 2.50 ;\right.$ range $\left.80^{\circ}-90^{\circ}\right)$ \\
\hline \multicolumn{3}{|l|}{ DASH score } \\
\hline - after 6 months & $14(\mathrm{SD} \pm 17.21 ;$ range $0-46.66)$ & $19(\mathrm{SD} \pm 22.28 ;$ range $0-79.16)$ \\
\hline - after 3 years & $8(\mathrm{SD} \pm 15.10 ;$ range $0-45.83)$ & $11(\mathrm{SD} \pm 23.49 ;$ range $0-83.33)$ \\
\hline \multicolumn{3}{|l|}{ VAS } \\
\hline - after 6 months & $1(\mathrm{SD} \pm 1.87 ;$ range $0-6)$ & $1(\mathrm{SD} \pm 1.98 ;$ range $0-8)$ \\
\hline - after 3 years & $1(\mathrm{SD} \pm 1.30 ;$ range $0-5)$ & $1(\mathrm{SD} \pm 2.05 ;$ range $0-8)$ \\
\hline \multicolumn{3}{|c|}{ X-ray postoperatively } \\
\hline radial inclination & $21^{\circ}\left(\mathrm{SD} \pm 4.3 ;\right.$ range $\left.11^{\circ}-26^{\circ}\right)$ & $22^{\circ}\left(\mathrm{SD} \pm 3.1 ;\right.$ range $\left.16^{\circ}-28^{\circ}\right)$ \\
\hline palmar tilt & $-11^{\circ}\left(\mathrm{SD} \pm 2.6\right.$, range $\left.-15^{\circ}--7^{\circ}\right)$ & $-10^{\circ}\left(\mathrm{SD} \pm 2.9\right.$, range $\left.-15^{\circ}--2^{\circ}\right)$ \\
\hline ulnar variance & $1 \mathrm{~mm}(\mathrm{SD} \pm 0.9 ;$ range $0 \mathrm{~mm}-3 \mathrm{~mm})$ & $1 \mathrm{~mm}$ (SD 1,2, range 0mm-4mm) \\
\hline \multicolumn{3}{|c|}{ X-ray 6 weeks postOP } \\
\hline radial inclination & $22^{\circ}(\mathrm{SD} \pm 4.4$, range $10-28)$ & $23^{\circ}\left(\mathrm{SD} \pm 2.9 ;\right.$ range $\left.16^{\circ}-28^{\circ}\right)$ \\
\hline palmar tilt & $-10^{\circ}\left(\mathrm{SD} \pm 2.9 ;\right.$ range $\left.-18^{\circ}--7^{\circ}\right)$ & $-10^{\circ}\left(\mathrm{SD} \pm 1.8 ;\right.$ range $\left.-13^{\circ}--6^{\circ}\right)$ \\
\hline ulnar variance & $0.5 \mathrm{~mm}(\mathrm{SD} \pm 0.9 ;$ range $0 \mathrm{~mm}-3 \mathrm{~mm})$ & $0.5 \mathrm{~mm}$ (SD 0.7 ; range $0 \mathrm{~mm}-2 \mathrm{~mm})$ \\
\hline
\end{tabular}


to massive alcohol abuse. No significant differences between the two groups were recorded with respect to follow-up time, DASH score, VAS or range of motion. 3 patients in the TTP group and 4 patients in the PPP group exhibited complete recovery of ROM after 6 months $\left(<5^{\circ}\right.$ side difference). There was no significant difference between the groups with respect to loss of ROM in the affected arm in comparison to the unaffected arm.

\section{DISCUSSION}

This study compared PEEK plates and standard titanium plates of similar design in the treatment of distal radius fracture. No significant differences were found during the 6 weeks follow up in radiological outcome and during the 3 years of clinical follow up.

Internal fixation with angle-stable plate osteosynthesis improves both, patient satisfaction and the functional outcome $(7,8)$ and operative treatment has been commoner during that time. We investigated the incidence of fractures of the distal radius and changing trends in surgical treatment during the period 2004-2010. Patients And Methods Registry data on 42,583 patients with a fracture of the distal radius from 2004 to 2010 were evaluated regarding diagnosis, age, sex, and surgical treatment. RESUlTs The crude incidence rate was 31 per 10 (4. In general, the established metal devices give similar results $(9,10)$, but additional studies are still needed to optimize treatment of displaced distal radius fractures. In particular, the comparison of different osteosynthesis materials, based on the established principle of angle-stability.

If the healing of the fracture is to be evaluated, it must be clearly visualised - particularly if recovery is protracted or when pseudarthrosis develops. On the other hand, metal implants may obscure the view, especially in a.p. X-rays (11) radiolucency, low artefacts on MRI or imaging scans and the high resistance associated to loading forces. The aim of this study was to evaluate the clinical and radiological results using a new Carbon-PEEK volar locking plate compared with titanium volar locking plates for the treatment of distal radius fractures. Methods And Material Thirty patients were included in this study. They all underwent traumatic intra-articular distal radius fractures and were surgi-cally treated with volar locking plates. The patients were randomly divided in two groups : In Group A (15 patients. Furthermore, problems with metal implants range from temperature sensitivity over persistent pain up to the development of CRPS (chronic regional pain syndrome). Changing the implant material could help to minimise these unwelcome side effects. CRF-PEEK is an innovative material with clear advantages in comparison to traditional metal plates, for the following reasons :

- It is radiolucent,

- the elastic modulus and strength are similar to normal bone,

- it is less rigid than titanium or stainless-steel plates and,

- no cold welding (12).

The clinical and radiological outcome results of the presented study are in line with those reported in other studies with traditional metal implants (13). Tarallo et al reported for PEEK implants a rate of complication similar to those occurring with different material (14). We found no complications related to the new material of the implant. No case of hardware breakage, loss of the surgical fracture reduction, infection or allergy was documented at follow-up. This is consistent with the results of Allemann et al reporting no adverse events and functionality satisfaction of the patients treated with a carbon-PEEK implant of the volar radius (15). In our study were no significant differences in ROM, neither in comparison of the injured versus the non-injured side nor in the comparison of the two different plates. There were no significant differences between the groups in VAS or DASH. Similar results with good clinical performance of Carbon-PEEK devices in orthopaedic and trauma surgery are presented in the literature $(11,16,17)$ radiolucency, low artefacts on MRI or imaging scans and the high resistance associated to loading forces. The aim of this study was to evaluate the clinical and radiological results using a new CarbonPEEK volar locking plate compared with titanium volar locking plates for the treatment of distal radius fractures. Methods AND Material Thirty patients were included in this study. They all underwent 
traumatic intra-articular distal radius fractures and were surgically treated with volar locking plates. The patients were randomly divided in two groups : In Group A 15 patients.

The major advantage of carbon-PEEK implants is their radiolucency, as this facilitates intraoperative anatomical reconstruction, as well as postoperative visualisation of the "osseous callus formation" in the X-ray (13). However, we found no difference in the accuracy of intraoperative reduction compared to the titanium plate.

Due to its radiolucency, carbon-peek implants allow direct visualisation of osseous callus formation, and facilitate more precise reposition and follow-up radiological controls (11) radiolucency, low artefacts on MRI or imaging scans and the high resistance associated to loading forces. The aim of this study was to evaluate the clinical and radiological results using a new Carbon-PEEK volar locking plate compared with titanium volar locking plates for the treatment of distal radius fractures. Methods And Material Thirty patients were included in this study. They all underwent traumatic intra-articular distal radius fractures and were surgically treated with volar locking plates. The patients were randomly divided in two groups : In Group A (15 patients. In the PPP group, one longitudinal fracture line after plating was detected, which would probably not have been detected in the TPP group due to the lack of radiolucency. The mobilisation of this patient was delayed and cast fixation was prolonged. The radius then healed without any further complication.

The cost of production of CFR-PEEK plates is higher, but the commercial price is in line with that of the metal systems (12).

The main drawback of this study is the small sample size of 31 patients. A statistical subgroup analysis in terms of AO types would have needed a larger sample.

In conclusion, this study showed that PEEK palmar plating performs as well as titanium plates with respect to ROM, DASH and VAS. In terms of clinical and radiological outcome, the two groups showed equivalent results at 3 years follow-up.

\section{REFERENCES}

1. Baidya KP, Ramakrishna S, Rahman M, Ritchie A. Quantitative radiographic analysis of fiber reinforced polymer composites. J Biomater Appl 2001 ; 15 : 279-89.

2. Akay M, Aslan N. An estimation of fatigue life for a carbon fibre/poly ether ether ketone hip joint prosthesis. Proc Inst Mech Eng H 1995 ; 209 : 93-103.

3. Peron M, Razavi SMJ, Torgersen J, Berto F. Fracture Assessment of PEEK under Static Loading by Means of the Local Strain Energy Density. Mater (Basel, Switzerland); 10. Epub ahead of print 13 December 2017

4. Steinberg EL, Rath E, Shlaifer A, Chechik O, Maman E, Salai M. Carbon fiber reinforced PEEK Optima-a composite material biomechanical properties and wear/debris characteristics of CF-PEEK composites for orthopedic trauma implants. J Mech Behav Biomed Mater $2013 ; 17: 221-8$.

5. Offenbaecher M, Ewert T, Sangha O, Stucki G. Validation of a German version of the disabilities of arm, shoulder, and hand questionnaire (DASH-G). J Rheumatol $2002 ; 29: 401-2$.

6. Germann G, Harth A, Wind G, Demir E. [Standardisation and validation of the German version 2.0 of the Disability of Arm, Shoulder,Hand (DASH) questionnaire]. Unfallchirurg $2003 ; 106: 13-9$.

7. Wilcke MKT, Hammarberg H, Adolphson PY. Epidemiology and changed surgical treatment methods for fractures of the distal radius : a registry analysis of 42,583 patients in Stockholm County, Sweden, 2004-2010. Acta Orthop 2013 ; 84 : 292-6.

8. Wilson J, Viner JJ, Johal KS, Woodruff MJ. Volar Locking Plate Fixations for Displaced Distal Radius Fractures : An Evaluation of Complications and Radiographic Outcomes. Hand (N Y) 2018 ; 13 : 466-472.

9. Spiteri M, Ng W, Matthews J, Power D. Functional Outcome of Fixation of Complex Intra-articular Distal Radius Fractures with a Variable-Angle Distal Radius Volar Rim Plate. J Hand Microsurg 2017 ; 9 : 11-16.

10. Thorninger R, Madsen ML, Wæver D, Borris LC, Rölfing JHD. Complications of volar locking plating of distal radius fractures in 576 patients with 3.2 years followup. Injury 2017 ; 48 : 1104-1109.

11. Perugia D, Guzzini M, Mazza D, Iorio C, Civitenga C, Ferretti A. Comparison between Carbon-Peek volar locking plates and titanium volar locking plates in the treatment of distal radius fractures. Injury 2017 ; 48 Suppl $3:$ S24-S29.

12. Tarallo L, Mugnai R, Adani R, Zambianchi F, Catani F. A new volar plate made of carbon-fiber-reinforced polyetheretherketon for distal radius fracture : analysis of 40 cases. J Orthop Traumatol 2014 ; 15 : 277-83.

13. Di Maggio B, Sessa $\mathbf{P}$, Mantelli $\mathbf{P}$, et al. PEEK radiolucent plate for distal radius fractures : multicentre clinical results at 12 months follow up. Injury 2017 ; 48 Suppl 3 : S34-S38. 
14. Tarallo L, Giorgini A, Novi M, Zambianchi F, Porcellini G, Catani F. Volar PEEK plate for distal radius fracture : analysis of adverse events. Eur J Orthop Surg Traumatol $2020 ; 30: 1293-1298$.

15. Allemann F, Halvachizadeh S, Rauer T, Pape HC. Clinical outcomes after carbon-plate osteosynthesis in patients with distal radius fractures. Patient Saf Surg 2019 ; $13: 30$.
16. Guzzini M, Lanzetti RM, Lupariello D, et al. Comparison between carbon-peek plate and conventional stainless steal plate in ankle fractures. A prospective study of two years follow up. Injury 2017 ; 48 : 1249-1252.

17. Gallagher EA, Lamorinière S, McGarry $P$. Finite element investigation into the use of carbon fibre reinforced PEEK laminated composites for distal radius fracture fixation implants. Med Eng Phys 2019 ; 67 : 22-32. 